\title{
Thermodynamics of Cadmium Sorption on Different Soils of West Bengal, India
}

\author{
Tanmoy Karak, ${ }^{1,2}$ Ranjit Kumar Paul, ${ }^{3}$ D. K. Das, ${ }^{1}$ Romesh K. Boruah, ${ }^{2}$ and Indira Sonar ${ }^{2}$ \\ ${ }^{1}$ Department of Agricultural Chemistry and Soil Science, Faculty of Agriculture, Bidhan Chandra Krishi Viswavidyalaya, Mohanpur, \\ Nadia, West Bengal 741252, India \\ ${ }^{2}$ Upper Assam Advisory Centre, Tea Research Association, Dikom, Assam 786101, India \\ ${ }^{3}$ Division of Statistical Genetics, Indian Agricultural Statistics Research Institute, New Delhi 110012, India
}

Correspondence should be addressed to Tanmoy Karak; tanmay.karak@gmail.com and Ranjit Kumar Paul; ranjitstat@gmail.com

Received 7 August 2013; Accepted 3 October 2013; Published 6 February 2014

Academic Editors: A. P. Borole and P. Grenni

Copyright (C) 2014 Tanmoy Karak et al. This is an open access article distributed under the Creative Commons Attribution License, which permits unrestricted use, distribution, and reproduction in any medium, provided the original work is properly cited.

A sorption study was conducted on different soils collected from five agroecological zones of West Bengal, India, to understand the soil environmental behavior and fate of cadmium. For this purpose batch adsorption experiments were carried out at the native soil $\mathrm{pH}$ and at three different temperatures $\left(25^{\circ} \mathrm{C}, 35^{\circ} \mathrm{C}\right.$, and $\left.45^{\circ} \mathrm{C}\right)$. The adsorption data fitted by a linear least squares technique to the different sorption isotherms. Most data obtained give the good fit to both Freundlich and modified Langmuir isotherms, but they are not consistent with the linear Langmuir adsorption model. Thermodynamic parameters, namely, thermodynamics equilibrium constant at a particular temperature $T\left(K_{T}^{0}\right)$, Gibbs free energy at a particular temperature $T\left(\Delta G_{T}^{0}\right)$, and change of enthalpy $\left(\Delta H^{0}\right)$ and change of entropy at temperature $T\left(\Delta S_{T}^{0}\right)$, were also determined by applying sorption value and concentrations of Cd in equilibrium solution within the temperature range. The thermodynamic parameters revealed that $\mathrm{Cd}$ sorption increases as the values of $K_{T}^{0}, \Delta G_{T}^{0}, \Delta H^{0}$, and $\Delta S_{T}^{0}$ were increased on reaction temperatures. The spontaneous sorption reaction can be concluded due to high values of $\Delta G_{T}^{0}$. The positive values of $\Delta H^{0}$ indicated that the Cd sorption is an endothermic one. Under these present conditions, the soil and its components possibly supply a number of sites having different adsorption energies for cadmium sorption.

\section{Introduction}

Contamination of heavy metals in soils is increasingly concerned in the last 6 decades [1-3]. In particular, cadmium $(\mathrm{Cd})$ is one of the most important toxic metals because of its rapid increase in soil environment [4], microbially or chemically undergraded characters, and easy uptake by plants and animals $[5,6]$, subsequently resulting in high ecological risk. An understanding of $\mathrm{Cd}$ sorption process and transport pathway is thus crucial for the assessment of $\mathrm{Cd}$ metal contamination in soil and reclamation of such polluted soils [7]. The sorption of Cd depends on soil characters and its component such as $\mathrm{Al}$-oxides, $\mathrm{Fe}$-oxides, goethite, organic matter, and other chemicals and mineralogical characteristics $[2,8-10]$. Despite their significant influences, temperature changes can exert an important action in regulating sorptiondesorption equilibrium and bioavailability of $\mathrm{Cd}$ in soils.
The sorption of heavy metals by soils has been extensively studied [10-12]. Results suggest that sorption appears to be a multi-step process involving an initial fast adsorption followed by a slow adsorption and diffusion into solid particles. The sorption of Cd into soil can be well described by a Freundlich or linear isotherm, whereas the closeness of Langmuir isotherm to the experimental results is lower [1315]. Estimation of the effect of individual components on the sorption of cadmium in soils can be drawn from different sorption isotherms.

The effect of temperature on Cd sorption at soil-water interface was also extensively studied $[2,16,17]$. Their results suggest that sorption of $\mathrm{Cd}$ in soil is favored at higher temperature. The equilibrium constant for the reaction at a particular reaction temperature $(T), K_{T}^{0}$, is related to the free energy change by $\Delta G_{T}^{0}=-R T \ln K_{T}^{0}$. Since $K_{T}^{0}$ increases with temperature in endothermic reactions, the formation 
TABLE 1: Physicochemical properties of the five experimental soils collected from different agroecological zones of West Bengal, India (data represent mean of tree replications $\pm \mathrm{SD})$.

\begin{tabular}{|c|c|c|c|c|c|}
\hline \multirow{2}{*}{ Property } & \multicolumn{5}{|c|}{ Soil } \\
\hline & $\mathrm{S}_{1}$ & $\mathrm{~S}_{2}$ & $\mathrm{~S}_{3}$ & $\mathrm{~S}_{4}$ & $\mathrm{~S}_{5}$ \\
\hline $\mathrm{pH}(1: 2.5) \mathrm{H}_{2} \mathrm{O}$ & $7.89 \pm 1.78$ & $8.09 \pm 3.27$ & $8.62 \pm 3.39$ & $6.02 \pm 1.14$ & $5.61 \pm 2.03$ \\
\hline O.C $\left(\mathrm{g} \mathrm{kg}^{-1}\right)$ & $7.03 \pm 1.05$ & $6.02 \pm 2.19$ & $5.21 \pm 1.79$ & $8.21 \pm 1.28$ & $8.65 \pm 3.17$ \\
\hline $\operatorname{CEC}\left[\mathrm{cmol}\left(\mathrm{p}^{+}\right) \mathrm{kg}^{-1}\right]$ & $22.13 \pm 3.79$ & $25.39 \pm 5.01$ & $29.87 \pm 2.19$ & $8.35 \pm 2.02$ & $6.14 \pm 2.15$ \\
\hline Clay (\%) & $39 \pm 7.78$ & $41 \pm 8.69$ & $48 \pm 4.37$ & $20 \pm 3.92$ & $18 \pm 1.78$ \\
\hline Sand (\%) & $14 \pm 3.67$ & $15 \pm 2.49$ & $18 \pm 1.75$ & $28 \pm 3.15$ & $31 \pm 3.13$ \\
\hline Silt (\%) & $47 \pm 6.67$ & $44 \pm 4.78$ & $34 \pm 5.17$ & $52 \pm 7.53$ & $51 \pm 6.35$ \\
\hline Texture & Silty clay loam & Silty clay & Clay & Silty loam & Silty loam \\
\hline Taxonomic classification & $\begin{array}{c}\text { Vertic } \\
\text { Ustochrept }\end{array}$ & $\begin{array}{c}\text { Typic } \\
\text { Haplumbrept }\end{array}$ & $\begin{array}{c}\text { Typic } \\
\text { Paleustalf }\end{array}$ & $\begin{array}{c}\text { Typic } \\
\text { Haplumbrept }\end{array}$ & $\begin{array}{c}\text { Typic } \\
\text { Haplaquest }\end{array}$ \\
\hline $\mathrm{CaCO}_{3}(\%)$ & $5.51 \pm 1.49$ & $5.62 \pm 1.09$ & $6.35 \pm 1.97$ & $0.59 \pm 0.07$ & $0.41 \pm 0.12$ \\
\hline DTPA extractable Cd $\left(\mathrm{mg} \mathrm{kg}^{-1}\right)$ & $0.004 \pm 0.001$ & $0.006 \pm 0.001$ & $0.008 \pm 0.001$ & $0.002 \pm 0.001$ & $0.001 \pm 0.001$ \\
\hline
\end{tabular}

of reaction products will be favored at high temperature. Therefore, a thermodynamic change in a reaction is more important to predict the reaction properties and direction of a reaction. Quantification of free energy changes $\left(\Delta G_{T}^{0}\right)$ at a particular temperature $(T)$ is also directly related to the transport of solute element from bulk solution into the appropriate site of the double layer or clay minerals lattice. It is also helpful to understand the sorption processes. Sposito investigated that thermodynamics approach can predict the sorption of metal from an initial nonequilibrium state to final state [18].

In view of the above, the present study was undertaken to understand the sorption behavior of Cd using conventional Langmuir, modified Langmuir, and Freundlich equations and to determine thermodynamic and sorption parameters for different soils collected from five agroecological zones of West Bengal, India.

\section{Materials and Methods}

Five soil samples with contrasting soil properties were collected from the A1 horizons of five agroecological zones in West Bengal, India (Figure 1).

The agroecological zones were Lakhsmikantapur series (Sample ID: $\mathrm{S}_{1}$ ), Kakdwip series (Sample ID: $\mathrm{S}_{2}$ ), Diamond harbor series (Sample ID: $S_{3}$ ), Chondrokona series (Sample ID: $\mathrm{S}_{4}$ ), and Bohorasol series (Sample ID: $\mathrm{S}_{5}$ ). The collected soils were air dried, sieved $(<2 \mathrm{~mm})$, and stored at room temperature in polyethylene bags. Twenty samples of each kind of soil were analyzed for physicochemical properties (Table 1). The $\mathrm{pH}$ and electrical conductivity of the samples were determined in saturated paste extracts [19]. The soil $\mathrm{pH}$ was carried out on soil slurries having soil: water ratios as 1:2.5 using a $\mathrm{pH}$ meter (Systronics India Ltd., model 239) and electrical conductivity (EC) was determined on soil slurries having soil: water ratios as 1:5 with a conductivity meter (Systronics India Ltd., model 507). Organic carbon and particle size distribution were analyzed by the WalkleyBlack method [19] and the international pipette method [20],

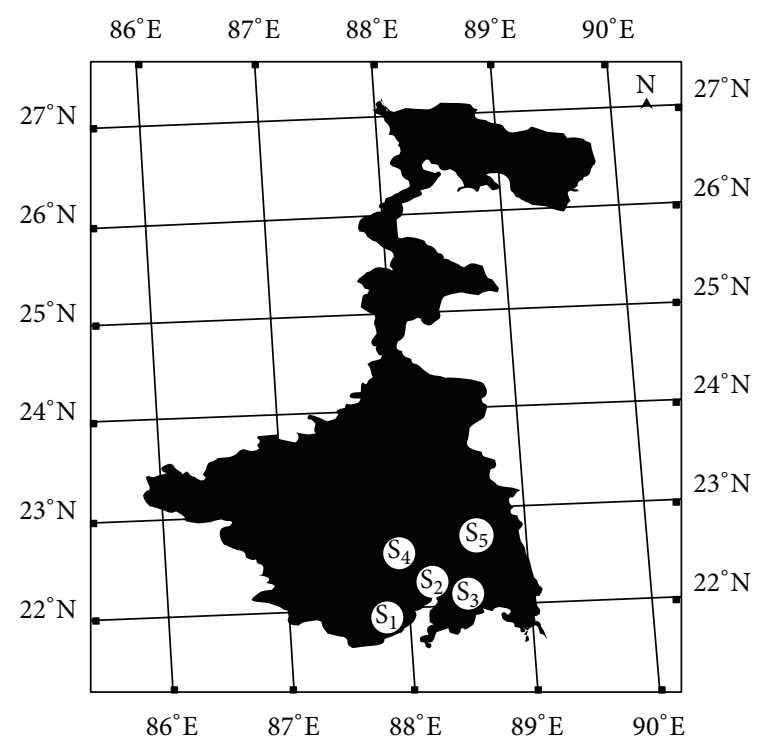

FIGURE 1: Location map (not in scale) of the sampling site. $S_{n}$ stands for sampling location.

respectively. $\mathrm{CaCO}_{3}$ was estimated by standard analytical methods as described by Page [21]. 0.005 M DTPA solutions were used to extract the available pool of cadmium, following the method as described by Lindsay and Norvell [22]. Briefly, $10 \mathrm{~mL}$ of $0.005 \mathrm{M}$ diethylene triamine pentaacetic acid (DTPA), $0.1 \mathrm{M}$ triethanolamine (TEA), and $0.01 \mathrm{M} \mathrm{CaCl}_{2}$ solution $(\mathrm{pH}=7.3)$ were added to $5 \mathrm{~g}$ of soil and the sample was shaken for $2 \mathrm{~h}$. After centrifugation $(4000 \mathrm{rpm}$ for $10 \mathrm{~min}$ ) the supernatant was filtered through $0.2 \mu \mathrm{m}$ Whatman filter paper in a $25 \mathrm{~mL}$ polycarbonate volumetric flask and diluted to $25 \mathrm{~mL}$ with deionized water.

For Cd sorption studies, $2 \mathrm{~g}$ soil sample (triplicate) was placed in $50 \mathrm{~mL}$ screw-capped polypropylene air tight centrifuge tube with $20 \mathrm{~mL} 0.025 \mathrm{~N} \mathrm{NaCl}$ solution having 5, 10, $15,20,25,30,35,40,50,60,75$, and $100 \mathrm{mg} \mathrm{Cd} \mathrm{L}^{-1}$ (final Cd 
concentrations). The centrifuge tubes were placed in temperature controlled orbital shaker to study the effect of reaction temperature at $25^{\circ} \mathrm{C}, 35^{\circ} \mathrm{C}$, and $45^{\circ} \mathrm{C}$. The equilibrium time for reaction was 25 hours. Original soil $\mathrm{pH}$ was maintained by addition of dilute $\mathrm{NaOH}$ or $\mathrm{HCl}$. To prevent the thin water layer on the soil colloid surface, the soil suspension was shaken every half an hour. At the end of reaction, the samples were centrifuged at $2500 \times \mathrm{g}$ for 5 minutes. Solution was filtered using $0.2 \mu \mathrm{m}$ Millipore filter paper and filtrate was stored at $4^{\circ} \mathrm{C}$. To prevent any microbial growth in filtrate, 2 drops of chloroform were added. After completion of all experiment the equilibrium concentrations $\left(C_{e}\right)$, as well as total and DTPA extractable Cd, were determined using atomic absorption spectrophotometer, model Varian Spectra 250 plus. The soil solid-phase $\mathrm{Cd}$ was calculated from the difference between initial Cd concentrations $\left(C_{i}\right)$ and those in solutions after equilibration. Statgraphics and computations and illustrations were made by using Statgraphics and Excel packages.

2.1. Evaluation of Sorption Data. The Langmuir and Freundlich equations are based on the kinetic theory of gases and are extensively used to describe gas adsorption on solids [23]. These equations are often applied to the adsorption of liquids and ions from solutions by solids.

The Langmuir adsorption equation can be written as

$$
\frac{x}{m}=\frac{k b C_{e}}{\left(1+k C_{e}\right)},
$$

where $x / m=$ amount of Cd adsorbed per unit weight of soil $\left[\mathrm{mg} \mathrm{kg}^{-1}\right], k=\mathrm{a}$ constant related to the binding energy $\left[\mathrm{dm}^{3} \mathrm{mg}^{-1}\right], b=$ adsorption maxima $\left[\mathrm{mg} \mathrm{kg}^{-1}\right]$, and $C_{e}=$ equilibrium $\mathrm{Cd}$ concentration in soil solution $\left[\mathrm{mg} \mathrm{dm}^{-3}\right]$. Equation (1) can be rearranged to give

$$
\frac{C_{e}}{(x / m)}=\left(\frac{1}{k b}\right)+\left(\frac{C_{e}}{b}\right) .
$$

Equation (2) is hereafter refered to as conventional Langmuir equation. A plot of $C_{e} /(x / m)$ versus $C_{e}$ gives a straight line from which $b$ (gradient ${ }^{-1}$ ) and $k$ (gradient/intercept) can be obtained.

The amount of Cd adsorbed by the soils was calculated using

$$
\left(\frac{x}{m}\right)=\frac{\left\{\left(C_{i}-C_{e}\right) / V\right\}}{W}+\mathrm{CV},
$$

where $C_{i}$ is the initial Cd concentration $\left(\mathrm{mg} \cdot \mathrm{dm}^{-3}\right), V$ is the volume of the initial solution, $\mathrm{dm}^{3}, W$ is the weight of a soil sample, $\mathrm{kg}$, and $\mathrm{CV}$ is the correction value (amount of $\mathrm{Cd}$ extracted by DTPA) (mg. $\left.\mathrm{kg}^{-1}\right)$; Freundlich equation can be written as follows:

$$
\log \left(\frac{x}{m}\right)=\log K_{f}+\left(\frac{1}{n}\right) \log C_{e},
$$

where $K_{f}$ and $1 / n$ denote the empirical Freundlich constant.
2.2. Thermodynamic Consideration of Sorption Reaction. The procedure outlined by Biggar and Cheung [24] was followed to calculate thermodynamics equilibrium constant at reaction temperature $T$ (absolute scale), $K_{T}^{0}$ and it can be formulated as

$$
K_{T}^{0}=\left(\frac{a_{s}}{a_{e}}\right)=\left(\frac{\lambda_{S} C_{S}}{\lambda_{e} C_{e}}\right),
$$

where $a_{s}=$ activity of adsorbed metal on soils at temperature $T, a_{e}=$ activity of metal in soil solution at equilibrium state at temperature $T, \gamma_{s}=$ activity coefficient of sorbed metal in soils at temperature $T, \gamma_{e}=$ activity coefficient of sorbed metal in solution at temperature $T, C_{s}=\mathrm{m}$ metal adsorbed per $\mathrm{L}$ of solution in contact with the soil surface at temperature $T$, $C_{e}=\mathrm{Mm}$ metal per $\mathrm{L}$ of solution at equilibrium in contact with the soil surface at temperature $T$.

At low concentrations, the activity coefficient approaches to the unity and (5) can be written as follows [7]:

$$
K_{T}^{0}=\frac{C_{s}}{C_{e}}
$$

The values of $K_{T}^{0}$ were obtained by plotting $C_{s}$ versus $C_{e}$ and extrapolating to zero $C_{s}$.

The standard Gibbs free energy at a particular temperature $T, \Delta G_{T}^{0}$, was calculated as follows:

$$
\Delta G_{T}^{0}=-R T \ln K_{T}^{0} .
$$

The change of enthalpy $\Delta H^{0}$ with change of reaction temperature range from $T_{i}$ to $T_{f}$ can be expressed as vant Hoff isochore (7)

$$
\frac{d\left(\ln K_{T}^{0}\right)}{d T}=\frac{\Delta H^{0}}{R T^{2}} .
$$

On integration within limit $K_{i}^{0}$ and $K_{f}^{0}$ with respective temperature range from $T_{i}$ to $T_{f}$ can be obtained

$$
\int_{K_{i}^{0}}^{K_{f}^{0}} d \ln K=\left(\frac{\Delta H^{0}}{R}\right) \int_{T_{i}}^{T_{f}} T^{-2} d T .
$$

Therefore,

$$
\Delta H^{0}=\left(\frac{R T_{i} T_{f}}{\left(T_{f}-T_{i}\right)}\right) \ln \left(\frac{K_{f}^{0}}{K_{i}^{0}}\right),
$$

where $K_{f}^{0}$ and $K_{i}^{0}$ are thermodynamics equilibrium constants at temperatures $T_{f}$ and $T_{i}$, respectively, where $T_{f}>T_{i}$ and $R$ is universal gas constant.

Determination of reaction enthalpy $\Delta H^{0}$ can be calculated from vant Hoff plot by $\ln K$ versus $1 / T$.

The change of entropy at temperature $T, \Delta S_{T}^{0}$, was calculated from the following:

$$
\Delta S_{T}^{0}=\frac{\left(\Delta H^{0}-\Delta G_{T}^{0}\right)}{T} .
$$


TABLE 2: Conventional Langmuir constants of Cd sorption in soils (data represent mean of tree replications \pm SD).

\begin{tabular}{|c|c|c|c|c|c|c|c|c|c|}
\hline \multirow{4}{*}{ Sample ID } & \multicolumn{9}{|c|}{ Temperature $\left({ }^{\circ} \mathrm{C}\right)$} \\
\hline & \multirow{2}{*}{\multicolumn{3}{|c|}{25}} & \multicolumn{3}{|c|}{35} & \multicolumn{3}{|c|}{45} \\
\hline & & & & \multicolumn{3}{|c|}{ Conventional Langmuir constants } & \multirow[b]{2}{*}{$b\left(\mathrm{mg} \mathrm{kg}^{-1}\right)$} & \multirow[b]{2}{*}{$k\left(\mathrm{~L} \mathrm{mg}^{-1}\right)$} & \multirow[b]{2}{*}{$R^{2}$} \\
\hline & $b\left(\mathrm{mg} \mathrm{kg}^{-1}\right)$ & $k\left(\mathrm{~L} \mathrm{mg}^{-1}\right)$ & $R^{2}$ & $b\left(\mathrm{mg} \mathrm{kg}^{-1}\right)$ & $k\left(\mathrm{~L} \mathrm{mg}^{-1}\right)$ & $R^{2}$ & & & \\
\hline $\mathrm{S}_{1}$ & $33.56 \pm 4.07$ & $0.027 \pm 0.001$ & $0.816^{*}$ & $37.74 \pm 7.17$ & $0.041 \pm 0.001$ & $0.828^{*}$ & $43.86 \pm 6.19$ & $0.045 \pm 0.001$ & $0.839^{*}$ \\
\hline $\mathrm{S}_{2}$ & $47.17 \pm 3.85$ & $0.029 \pm 0.001$ & $0.827^{*}$ & $53.76 \pm 3.04$ & $0.041 \pm 0.001$ & $0.844^{*}$ & $61.35 \pm 7.71$ & $0.055 \pm 0.001$ & $0.874^{*}$ \\
\hline $\mathrm{S}_{3}$ & $84.03 \pm 7.78$ & $0.027 \pm 0.002$ & $0.844^{*}$ & $89.29 \pm 7.78$ & $0.037 \pm 0.001$ & $0.860^{*}$ & $99.01 \pm 8.79$ & $0.045 \pm 0.001$ & $0.875^{*}$ \\
\hline $\mathrm{S}_{4}$ & $28.57 \pm 3.79$ & $0.022 \pm 0.002$ & $0.814^{*}$ & $29.59 \pm 3.33$ & $0.031 \pm 0.001$ & $0.797^{*}$ & $34.97 \pm 6.13$ & $0.038 \pm 0.001$ & $0.805^{*}$ \\
\hline $\mathrm{S}_{5}$ & $24.39 \pm 3.07$ & $0.018 \pm 0.001$ & $0.810^{*}$ & $26.11 \pm 4.02$ & $0.023 \pm 0.001$ & $0.784^{*}$ & $28.57 \pm 2.07$ & $0.034 \pm 0.001$ & $0.791^{*}$ \\
\hline
\end{tabular}

${ }^{*}$ Significant at $0.05 \%$ level.

\section{Results and Discussion}

Soil samples used in the study differed significantly in their physical and chemical properties (Table 1). Cation exchange capacity (CEC) varied from 6.14 to $29.87\left(\mathrm{cmol}\left(\mathrm{p}^{+}\right) \mathrm{kg}^{-1}\right)$ with soils, representing mostly acidic to basic reaction. The physical chemical properties show that $S_{1}, S_{2}$, and $S_{3}$ are alkaline in nature, whereas $S_{4}$ and $S_{5}$ are acidic in nature.

The five soil samples varied appreciably in their ability to sorb added cadmium in soil solution irrespective of initial Cd concentrations affected by reaction temperatures (Figure 2).

The sorption ability increases with rise in temperature. In all experimental soils the sorption was appreciable and changes at high reaction temperature, that is, $45^{\circ} \mathrm{C}$. The highest $\mathrm{Cd}(9.14 \%)$ was adsorbed by soil $\mathrm{S}_{3}$ at $45^{\circ} \mathrm{C}$, whereas this value was only $2.6 \%$ for $S_{5}$ at the same temperature at $C_{i}$ of $100 \mathrm{mg} \mathrm{L}^{-1}$. These values were 6.9 and $1.8 \%$ for soils $\mathrm{S}_{3}$ and $\mathrm{S}_{5}$ at $25^{\circ} \mathrm{C}$, whereas these values were 7.9 and $2.1 \%$ at $35^{\circ} \mathrm{C}$, respectively. Percent adsorption was more pronounced at low $C_{i}$. Soil, $\mathrm{S}_{3}$, has more sorption capacity versus the other soils. Sorption capacity follows the sequence $S_{3}>S_{2}>$ $\mathrm{S}_{1}>\mathrm{S}_{4}>\mathrm{S}_{5}$. The increasing temperature increases the sorption of $\mathrm{Cd}$ in soil because temperature may increase the rate of aggregation of suspended materials which may cause the adsorption in faster rate. The sorption ability of five soils increased with increase in clay content, $\mathrm{pH}$, and calcium carbonate percentage. The increased sorbed capacity of soil with presence of increased amount of clay may be due to high charge density of both the planer [25] and edge sites [26]. On the other hand this high charge density leads to a greater dehydration to fasten $\mathrm{Cd}^{2+}$ ion mobility from soil solution to soil [27]. Sorption of Cd with increase in soil $\mathrm{pH}$ also plays a crucial role because it directly controls the solubility of cadmium hydroxides as well as its carbonates and phosphates [28]. Sorption of $\mathrm{Cd}$ was more at high $\mathrm{pH}$. This is because of less competition from $\mathrm{H}_{3} \mathrm{O}^{+}$ions compared to soils having low pH [29]. Reed et al. [30] also reported similar observations. The increase of $\mathrm{Cd}$ sorption with increasing soil $\mathrm{pH}$ increases $\mathrm{Cd}^{2+}$ retention of soil surface via adsorption, inner sphere surface complexation, and/or precipitation and multinuclear type reactions [31]. Cadmium (II) is a closed shell cation having complete valence orbital $\left(5 \mathrm{~d}^{10}\right)$ which favors columbic type attraction at soil surface for sorption as opposed to inner sphere surface reactions through sharing of electrons [32] and which also may contribute to our findings. $\mathrm{CEC}$ also affect sorption of Cd. Among these soils, the one having low CEC sorbed much less $\mathrm{Cd}$ than that having high CEC. Singh et al. [33] also observed that CEC plays an important role in the sorption of $\mathrm{Cd}$ in soils.

Every $10^{\circ} \mathrm{C}$ increase in temperature, percentage Cd sorption increases 5.8 to $6.19 \%$ for $S_{1}, 6$ to $6.9 \%$ for $S_{2}, 7.6$ to $11.11 \%$ for $S_{3}, 3.8$ to $5.0 \%$ for $S_{4}$, and 1.8 to $2.6 \%$ for $S_{5}$ from higher to lower concentration of added $\mathrm{Cd}$. The increase in sorption with rise in temperature indicates that $\mathrm{Cd}$ sorption is exothermic in nature (see later in thermodynamic approach). The marked effect of Cd sorption with temperature was found in acidic soils $\left(S_{4}\right.$ and $\left.S_{5}\right)$ versus alkaline soils $\left(S_{1}, S_{2}\right.$, and $\left.S_{3}\right)$. The results from this study corroborated with those reported by Almås et al. [16]. Increasing temperature enhances the rate of metal reaction with soil constituents [16] and this effect has been ascribed to a diffusion-controlled metal penetration in the mineral structure [34]. The general explanation can also be recognized from our experiment on the adsorption of $\mathrm{Cd}$ in soil that increases with temperature due to the decrease in the activation energy of sorption reaction which promotes the sorption kinetics.

Cadmium sorption on soils also depends on the presence of organic carbon in soils. The sorption of $\mathrm{Cd}$ by different soils decreases with increase in organic carbon. This may be due to the formation of stable soluble metal-organic complex with soil organic matter facilitating the persistence of $\mathrm{Cd}$ in soil solution [35]. The increased temperature may also have facilitated the biological degradation of organic materials, which may be the possible reason of the observed fact.

3.1. Modeling of Sorption Data. For all experimental soils, sorption data of Cd was initially tried to be fitted in conventional Langmuir equation (2) to predict the behavior of $\mathrm{Cd}$ sorption in soils (Table 2 ). The values of sorption maxima (b) ranged from 24.39 to $99.01 \mathrm{mg} \mathrm{kg}^{-1}$. In all cases, a sorption maximum $(b)$ was increased with rise in temperature. Percent increase of $b$ from $25^{\circ} \mathrm{C}$ to $35^{\circ} \mathrm{C}$ and $35^{\circ} \mathrm{C}$ to $45^{\circ} \mathrm{C}$ was 6.26 and 10.89 for soil $S_{1}, 13.97$ and 14.12 for $S_{2}, 12.46$ and 16.22 for soil $S_{3}, 3.57$ and 18.18 for $S_{4}$, and 7.05 and 9.42 for $S_{5}$ soil. Sorption was maximum for soil $S_{3}$ due to higher clay content. Bolton and Evans [36] also reported that clay content in soil was significantly correlated to sorption maximum. Pronounced change of $b$ in soil $S_{4}$ may be due 


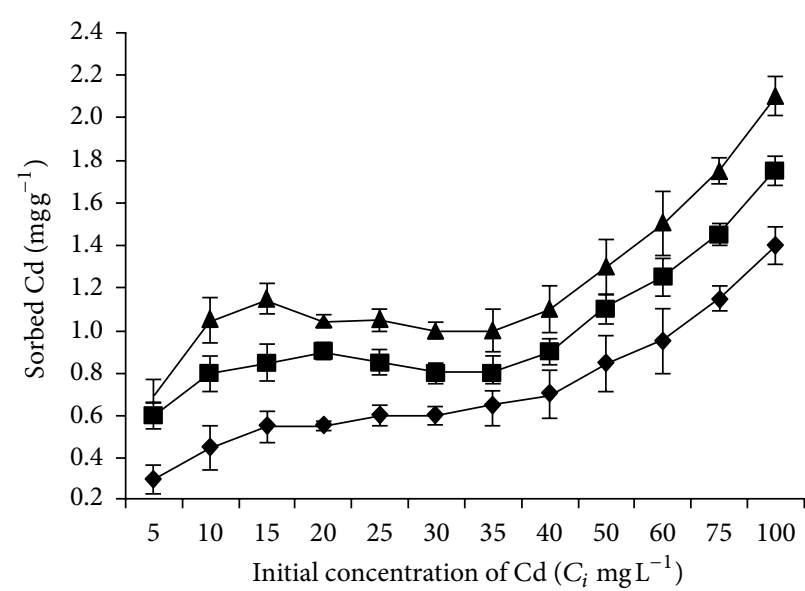

(a)

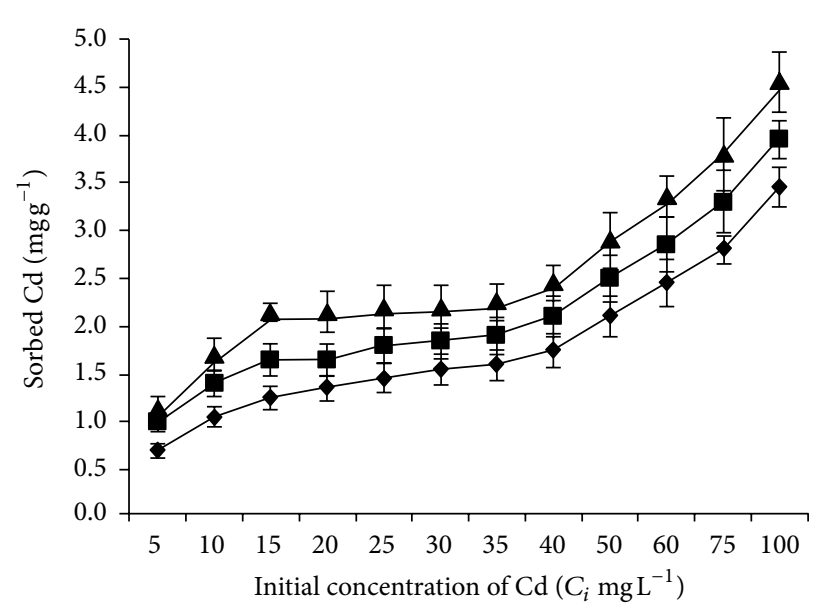

(c)

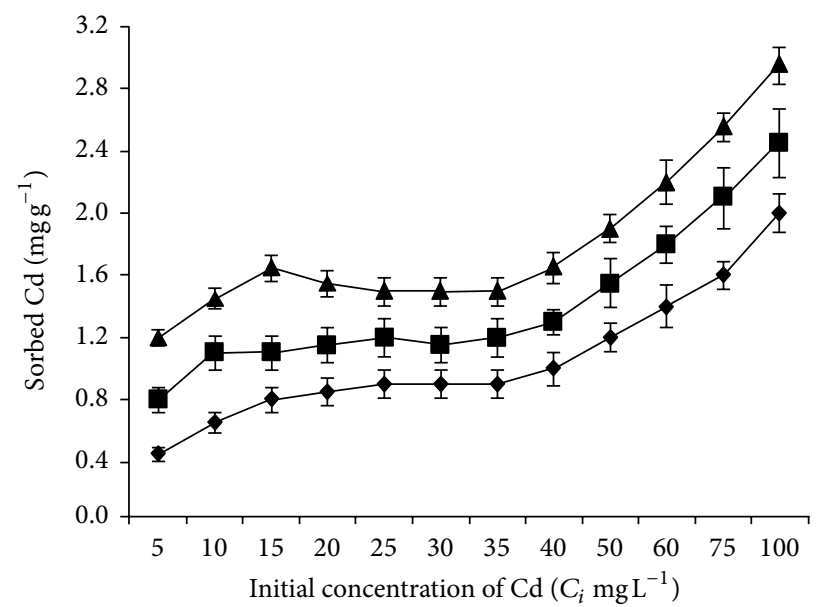

(b)

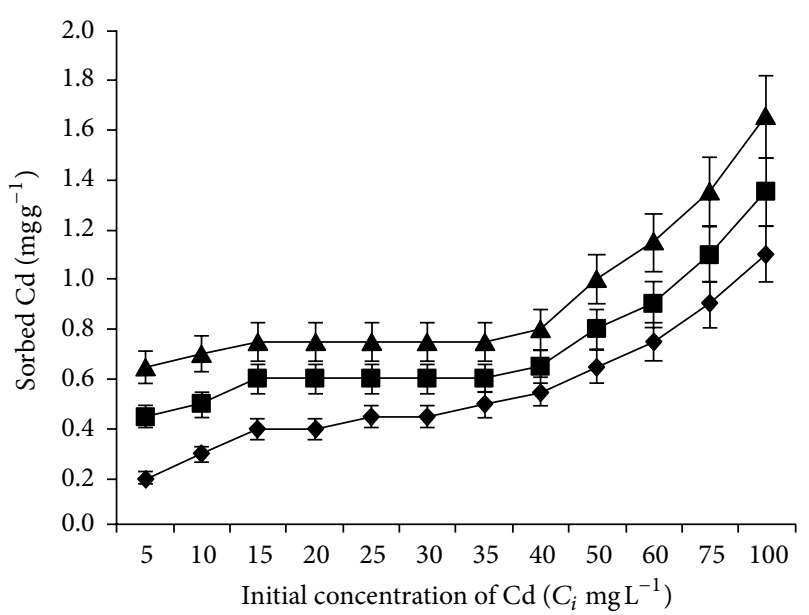

(d)

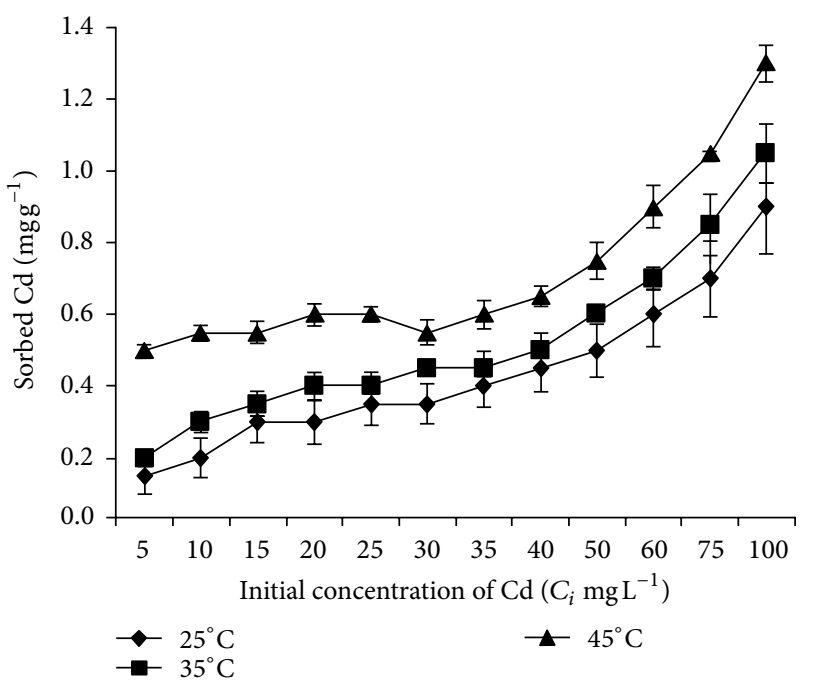

(e)

Figure 2: Amount of $\mathrm{Cd}$ adsorbed at equilibrium as a function of three different temperatures for the experimental soils [(a) $S_{1}$, (b) $S_{2}$, (c) $\mathrm{S}_{3}$, (d) $\mathrm{S}_{4}$, and (e) $\mathrm{S}_{5}$ ] at different Cd concentrations. 
TABLE 3: Modified Langmuir constants of Cd sorption in soils (data represent mean of tree replications \pm SD).

\begin{tabular}{|c|c|c|c|c|c|c|c|}
\hline \multirow{3}{*}{ Sample ID } & \multirow{3}{*}{ Temperature $\left({ }^{\circ} \mathrm{C}\right)$} & \multicolumn{6}{|c|}{ Modified Langmuir constants } \\
\hline & & \multicolumn{3}{|c|}{ Part I curve } & \multicolumn{3}{|c|}{ Part II curve } \\
\hline & & $b_{\mathrm{I}}\left(\mathrm{mg} \mathrm{kg}^{-1}\right)$ & $k_{\mathrm{I}}\left(\mathrm{L} \mathrm{mg}^{-1}\right)$ & $R^{2}$ & $b_{\text {II }}\left(\mathrm{mg} \mathrm{kg}^{-1}\right)$ & $k_{\mathrm{II}}\left(\mathrm{L} \mathrm{mg}^{-1}\right)$ & $R^{2}$ \\
\hline \multirow{3}{*}{$S_{1}$} & 25 & $14.26 \pm 2.73$ & $0.19 \pm 0.001$ & $0.998^{* *}$ & $81.97 \pm 5.19$ & $0.005 \pm 0.001$ & $0.999^{* *}$ \\
\hline & 35 & $17.06 \pm 2.97$ & $2.08 \pm 0.051$ & $0.992^{* *}$ & $88.50 \pm 4.07$ & $0.007 \pm 0.001$ & $0.994^{* *}$ \\
\hline & 45 & $20.37 \pm 3.01$ & $9.26 \pm 1.93$ & $0.991^{* *}$ & $97.09 \pm 3.79$ & $0.008 \pm 0.001$ & $0.999^{* *}$ \\
\hline \multirow{3}{*}{$\mathrm{S}_{2}$} & 25 & $21.28 \pm 3.09$ & $0.20 \pm 0.001$ & $0.997^{* *}$ & $111.11 \pm 7.17$ & $0.006 \pm 0.001$ & $0.992^{* *}$ \\
\hline & 35 & $24.75 \pm 2.73$ & $0.76 \pm 0.001$ & $0.999^{* *}$ & $114.94 \pm 7.91$ & $0.008 \pm 0.001$ & $0.992^{* *}$ \\
\hline & 45 & $30.67 \pm 4.07$ & $11.24 \pm 1.78$ & $0.997^{* *}$ & $116.28 \pm 11.83$ & $0.011 \pm 0.001$ & $0.994^{* *}$ \\
\hline \multirow{3}{*}{$\mathrm{S}_{3}$} & 25 & $38.02 \pm 3.71$ & $0.15 \pm 0.001$ & $0.999^{* *}$ & $172.41 \pm 14.07$ & $0.007 \pm 0.001$ & $0.994^{* *}$ \\
\hline & 35 & $42.37 \pm 5.09$ & $0.27 \pm 0.001$ & $0.998^{* *}$ & $175.44 \pm 13.19$ & $0.009 \pm 0.001$ & $0.999^{* *}$ \\
\hline & 45 & $49.26 \pm 6.31$ & $0.40 \pm 0.001$ & $0.997^{* *}$ & $188.68 \pm 11.11$ & $0.010 \pm 0.001$ & $0.995^{* *}$ \\
\hline \multirow{3}{*}{$\mathrm{S}_{4}$} & 25 & $12.39 \pm 2.07$ & $0.12 \pm 0.001$ & $0.998^{* *}$ & $67.57 \pm 6.37$ & $0.005 \pm 0.001$ & $0.990^{* *}$ \\
\hline & 35 & $12.52 \pm 2.56$ & $0.79 \pm 0.003$ & $0.998^{* *}$ & $79.37 \pm 8.19$ & $0.005 \pm 0.001$ & $0.995^{* *}$ \\
\hline & 45 & $15.11 \pm 1.73$ & $4.80 \pm 1.09$ & $0.999^{* *}$ & $90.91 \pm 6.67$ & $0.006 \pm 0.001$ & $0.996^{* *}$ \\
\hline \multirow{3}{*}{$\mathrm{S}_{5}$} & 25 & $10.49 \pm 1.03$ & $0.08 \pm 0.001$ & $0.995^{* *}$ & $56.82 \pm 7.07$ & $0.004 \pm 0.001$ & $0.973^{* *}$ \\
\hline & 35 & $10.66 \pm 1.11$ & $0.16 \pm 0.007$ & $0.999^{* *}$ & $71.43 \pm 3.79$ & $0.004 \pm 0.001$ & $0.994^{* *}$ \\
\hline & 45 & $11.90 \pm 1.23$ & $1.26 \pm 0.001$ & $0.999^{* *}$ & $76.92 \pm 4.09$ & $0.005 \pm 0.001$ & $0.996^{* *}$ \\
\hline
\end{tabular}

** Significant at $1 \%$ level.

to more dissolution of organic acids present in soil and the more competition between $\mathrm{H}^{+}$and $\mathrm{Cd}^{2+}$ contributes to the observed fact. Results from this experiment bear similarities to those reported by Bruemmer et al. [37]. They also found that the adsorption of $\mathrm{Cd}$ on soil increases with increase of sorption reaction temperature.

The affinity of metal bonding varied with soil types and sorption temperature. Bonding energy $(k)$ increases with increase in temperature and ranges from 0.018 to $0.055 \mathrm{~L} \mathrm{mg}^{-1}$. The results are very much similar to those reported by Adhikari and Singh [7]. Increasing $k$ with rise in temperature not only indicates the increased sorption but also indicates that at higher temperature sorption of Cd in soil may shift from physisorption to chemisorptions [31].

The Langmuir one-site isotherm is conceptually valid for monolayer sorption on a surface containing a finite number of binding sites. Moreover, the treatment assumes uniform energies of sorption on the surface and no transmigration of adsorbates into the plane of the surface. Such restrictions are not applicable to solids characterized by heterogeneous adsorptive surface like those found in soil systems. Data analysis and interpretations solely on Langmuir adsorption maximum (b) should be undertaken with care since it does not outline some sorption particularities as illustrated in figures (Figures 3(a), 3(b), 3(c), 3(d), and 3(e)).

When the sorption data were plotted according to the conventional Langmuir equation (2), the frequently reported linear relationship was obtained for equilibrium concentration $\left(C_{e}\right)$ lower than $33.74,33.35$, and $33 \mathrm{mg} \mathrm{L}^{-1}$ for $\mathrm{S}_{1}, 33.17$, 32.64, and $31.95 \mathrm{mg} \mathrm{L}^{-1}$ for $\mathrm{S}_{2}, 31.84,31.18$, and $30.15 \mathrm{mg} \mathrm{L}^{-1}$ for $\mathrm{S}_{3}, 34.00,33.80$, and $33.51 \mathrm{mg} \mathrm{L}^{-1}$ for $\mathrm{S}_{4}, 34.21,34.09$, and $33.83 \mathrm{mg} \mathrm{L}^{-1}$ for $\mathrm{S}_{5}$ at $25^{\circ} \mathrm{C}, 35^{\circ} \mathrm{C}$, and $45^{\circ} \mathrm{C}$, respectively (Figures 3(a), 3(b), 3(c), 3(d), and 3(e)). Above those values of $C_{e}$ the linearity of curves follows another path. These deviations also follow the linear Langmuir relationship, which suggest that the existence in each soil with different temperature has two sites of adsorption populations. These two different sites have widely differing affinity for $\mathrm{Cd}$, each of which can be described by two-site Langmuir relationship having varied $k$ and $b$ values. To describe this phenomenon, $C_{e} /(x / m)$ versus $C_{e}$ curve (2) was resolved into two-site equation using modified Langmuir sorption equation described by Syers et al. [38]. Consider the following:

$$
\begin{aligned}
\frac{C_{e}}{(x / m)}= & k_{\mathrm{I}} b_{\mathrm{I}}\left(\frac{C_{e}}{\left(1+k_{\mathrm{I}} C_{e}\right)}\right) \\
& +k_{\mathrm{II}} b_{\mathrm{II}}\left(\frac{C_{e}}{\left(1+k_{\mathrm{II}} C_{e}\right)}\right) \text { modified Langmuir. }
\end{aligned}
$$

The values of coefficients $k_{\mathrm{I}}$ and $b_{\mathrm{I}}$ for part I curve and $k_{\mathrm{II}}$ and $b_{\mathrm{II}}$ for part II curve were calculated to know the sorption maxima and bonding energy separately using regression equations (Table 3). Modified Langmuir equation give better fit for Cd sorption $\left(R^{2}=0.990-0.999^{* *}\right)$ than conventional Langmuir equation $\left(R^{2}=0.784-0.875\right)$ in all ranges of sorption temperatures. Harter and Baker [39] suggested that the modified Langmuir isotherm provides better linearity rather than conventional Langmuir isotherm, because the former considers the ratio of adsorbed and desorbed cations. The adsorption maxima for part I $\left(b_{\mathrm{I}}\right)$ was smaller versus part II $\left(b_{\text {II }}\right)$ irrespective of treatment and temperature for all the soils. Adsorption maxima for part I $\left(b_{\mathrm{I}}\right)$ was found for $\mathrm{S}_{3}$ at $45^{\circ} \mathrm{C}\left(49.26 \mathrm{mg} \mathrm{kg}^{-1}\right)$ and it was minimum for $S_{5}\left(11.90 \mathrm{mg} \mathrm{kg}^{-1}\right)$. At $25^{\circ} \mathrm{C}$ and $35^{\circ} \mathrm{C}$ it was 38.02 and $42.37 \mathrm{mg} \mathrm{kg}^{-1}$ for $\mathrm{S}_{3}$, whereas 10.49 and $10.66 \mathrm{mg} \mathrm{kg}^{-1}$ were obtained for $\mathrm{S}_{5}$. A highest adsorption maximum for part II $\left(b_{\text {II }}\right)$ was for $\mathrm{S}_{3}$ at $45^{\circ} \mathrm{C}\left(188.61 \mathrm{mg} \mathrm{kg}^{-1}\right)$ 


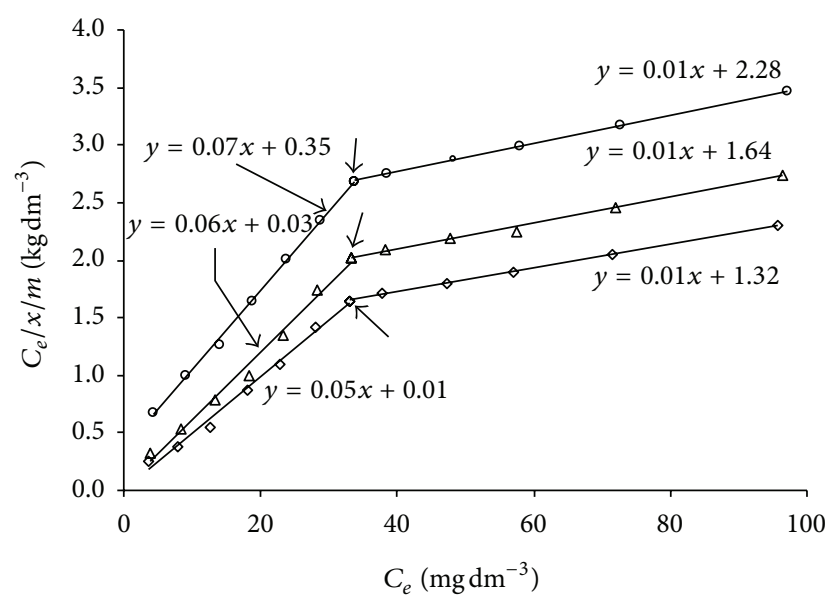

(a)

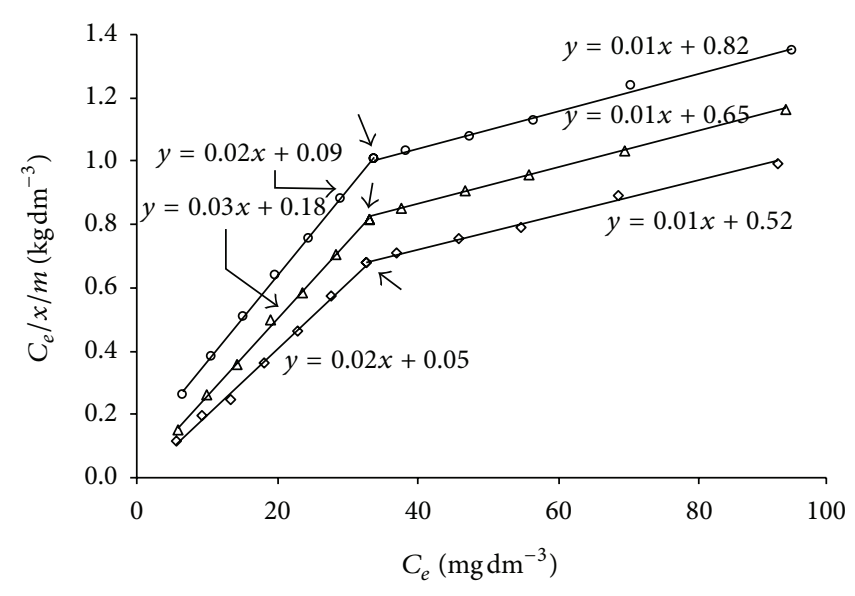

(c)

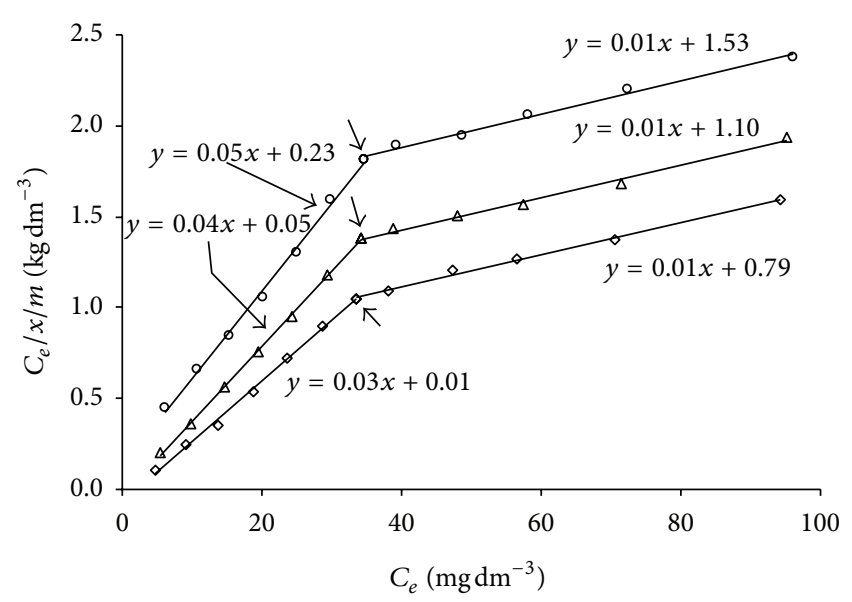

(b)

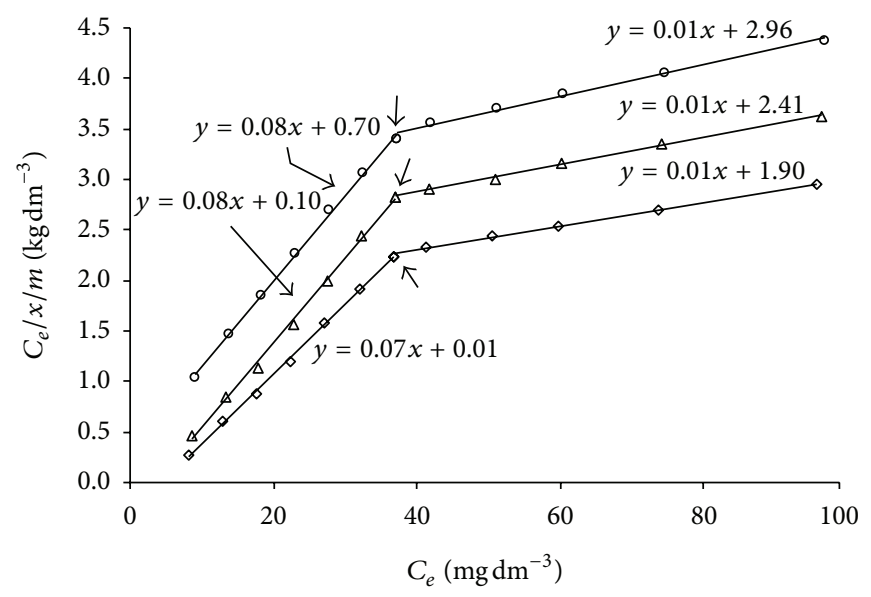

(d)

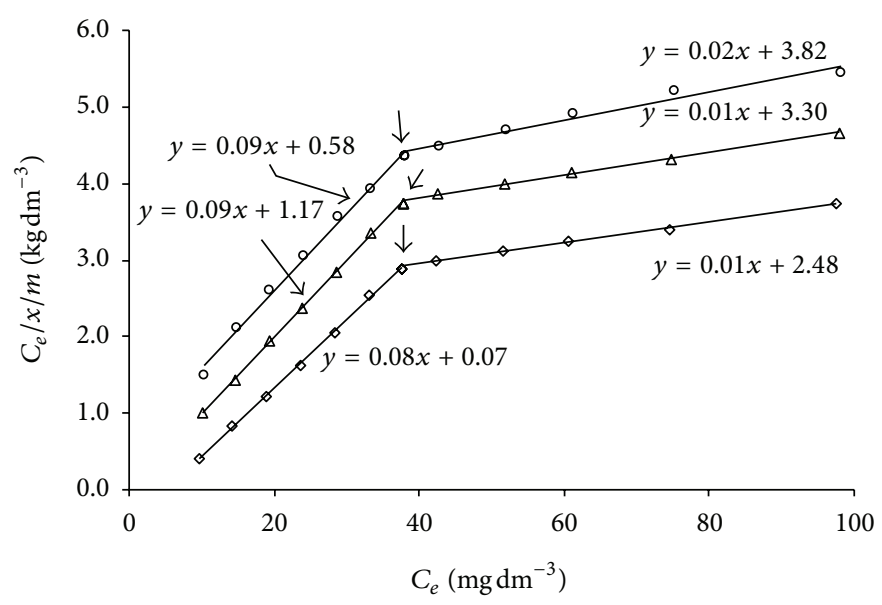

(e)

FIGURE 3: Isotherm for the sorption of added Cd by the soils obtained using the conventional Langmuir equation; breaks in the isotherms are indicated by arrows and line of each plot represents modified Langmuir equation. (a) $S_{1}$, (b) $S_{2}$, (c) $S_{3}$, (d) $S_{4}$, and (e) $S_{5}$. - - - , - $\Delta-$, and - $\diamond$ for 25,35 , and $45^{\circ} \mathrm{C}$. 
TABLE 4: Freundlich constants of Cd sorption in soils (data represent mean of tree replications \pm SD).

\begin{tabular}{|c|c|c|c|c|}
\hline \multirow{2}{*}{ Sample ID } & \multirow{2}{*}{ Temperature $\left({ }^{\circ} \mathrm{C}\right)$} & \multicolumn{3}{|c|}{ Freundlich constants } \\
\hline & & $K_{f}$ & $n$ & $R^{2}$ \\
\hline \multirow{3}{*}{$\mathrm{S}_{1}$} & 25 & $3.228 \pm 1.17$ & $2.298 \pm 1.05$ & $0.934^{* *}$ \\
\hline & 35 & $2.503 \pm 1.71$ & $3.763 \pm 2.01$ & $0.925^{* *}$ \\
\hline & 45 & $10.028 \pm 2.13$ & $3.824 \pm 1.36$ & $0.981^{* *}$ \\
\hline \multirow{3}{*}{$\mathrm{S}_{2}$} & 25 & $4.833 \pm 1.22$ & $2.339 \pm 1.24$ & $0.937^{* *}$ \\
\hline & 35 & $10.447 \pm 2.19$ & $3.419 \pm 1.65$ & $0.952^{* *}$ \\
\hline & 45 & $17.968 \pm 3.17$ & $4.771 \pm 1.24$ & $0.931^{* *}$ \\
\hline \multirow{3}{*}{$\mathrm{S}_{3}$} & 25 & $7.264 \pm 2.13$ & $2.145 \pm 1.05$ & $0.965^{* *}$ \\
\hline & 35 & $12.362 \pm 1.78$ & $2.685 \pm 1.04$ & $0.930^{* *}$ \\
\hline & 45 & $16.413 \pm 4.01$ & $2.899 \pm 1.10$ & $0.916^{* *}$ \\
\hline \multirow{3}{*}{$\mathrm{S}_{4}$} & 25 & $1.938 \pm 0.27$ & $1.996 \pm 0.99$ & $0.964^{* *}$ \\
\hline & 35 & $4.899 \pm 1.11$ & $3.171 \pm 1.50$ & $0.901^{* *}$ \\
\hline & 45 & $7.998 \pm 2.17$ & $4.117 \pm 2.05$ & $0.945^{* *}$ \\
\hline \multirow{3}{*}{$\mathrm{S}_{5}$} & 25 & $1.241 \pm 0.01$ & $1.808 \pm 1.09$ & $0.979^{* *}$ \\
\hline & 35 & $2.079 \pm 0.07$ & $2.155 \pm 1.00$ & $0.935^{* *}$ \\
\hline & 45 & $5.451 \pm 1.78$ & $3.588 \pm 2.04$ & $0.952^{* *}$ \\
\hline
\end{tabular}

** Significant at $1 \%$ level.

and it was minimum for $\mathrm{S}_{5}\left(76.92 \mathrm{mg} \mathrm{kg}^{-1}\right)$. At $25^{\circ} \mathrm{C}$ and $35^{\circ} \mathrm{C}$ it was 172.41 and $175.44 \mathrm{mg} \mathrm{kg}^{-1}$ for $\mathrm{S}_{3}$, while the same was 56.82 and $71.43 \mathrm{mg} \mathrm{kg}^{-1}$ for $\mathrm{S}_{5}$. The values of $b$, obtained by using modified Langmuir adsorption isotherm, follow the same trend observed in conventional Langmuir equation. Cadmium sorption maxima for part I $\left(b_{I}\right)$ was five times less than that of part II $\left(b_{\mathrm{II}}\right)$. This deviation may be due to the high initial concentration $\left(C_{i}\right)$ of $\mathrm{Cd}$. Lower values of $b_{\mathrm{I}}$ on part I curve may be due to the less adsorption of $\mathrm{Cd}$ on soil surface up to $C_{i}$ equal to $35 \mathrm{mg} \mathrm{L}^{-1}$ whereas higher values of $b_{\text {II }}$ on part II curve may be due to high cadmium adsorption on soil. The ranges of $k_{\mathrm{I}}$ and $k_{\mathrm{II}}$ were 0.08 to 11.24 and 0.005 to $0.01 \mathrm{mg} \mathrm{L}^{-1}$, respectively. The high value of $k_{\mathrm{I}}$ indicate the strong bonding between $\mathrm{Cd}$ and soil particles prevailing chemisorption on soil surface and it mainly rises up to $35 \mathrm{mg} \mathrm{L}^{-1}$ as $\mathrm{Cd}$ is added in all experimental soils irrespective of reaction temperature. On other hand the lower value of $k_{\mathrm{II}}$ conforms the physisorption of $\mathrm{Cd}$ on soil surface along with the precipitation of $\mathrm{Cd}$ at high soil $\mathrm{pHs}$. The values of $k_{\mathrm{I}}$ and $k_{\mathrm{II}}$ also suggest that there are at least two forms of $\mathrm{Cd}$ sorbed on soils. The one at low concentrations $\left(C_{i}=\right.$ $35 \mathrm{mg} \mathrm{L}^{-1} \mathrm{Cd}$ ) represents specially sorbed $\mathrm{Cd}$ at high energy surfaces having low dissociation constant. The other one at high metal concentrations $\left(C_{i}>35 \mathrm{mg} \mathrm{L}^{-1}\right)$ may be the indicative of loosely held metal at low energy surfaces having high dissociation constant or precipitation as suggested by Adhikari and Singh [7]. Thus differences in bonding affinity for $\mathrm{Cd}$ among all soil types were more prominent at low level of Cd pollution.

Table 4 shows the Freundlich constants of $\mathrm{Cd}$ sorption isotherms of five different agroecological top soils in the $\mathrm{pH}$ range of 5.61-8.62. Freundlich adsorption isotherm better fits the data $\left(R^{2}=0.901-0.981^{* *}\right)$ versus the Langmuir isotherm $\left(R^{2}=0.791-0.875^{* *}\right)$. For all experimental soils the values of $K_{f}$ and $n$ were greater at higher temperatures. The values of
$K_{f}$ were $>17.968$ for $\mathrm{S}_{2}$ at $45^{\circ} \mathrm{C}$ whereas it was $<1.241$ for $\mathrm{S}_{5}$ at $25^{\circ} \mathrm{C}$. All $K_{f}$ values were $>1$. Another constant $n$ follows the same trend like $K_{f}$.

3.2. Thermodynamic Variables of Cadmium Sorption in Soils. Vant Hoff's equation (10) provides a way of measuring the enthalpy of a reaction without using calorimeter. Equilibrium compositions are measured over a range of temperature (at constant pressure), and $\ln K$ is plotted against $1 / T$. It is revealed from (10) that the slope is $-\Delta H^{0} / R$. On account of the temperature dependence of the reaction enthalpy, this slope depends on the temperature and so the line is not expected to be perfectly straight. In practice, however, $\Delta H^{0}$ normally depends only weakly on the temperature [23]. On sorption experiments of $\mathrm{Cd}$ in soil, it was found that the sorption of $\mathrm{Cd}$ increases with temperature, and therefore according to Le Chatelier's principle, the sorption of $\mathrm{Cd}$ in soil is endothermic one. In order to find the reason for behavior of $\mathrm{Cd}$ sorption in soils we need to look for thermodynamics variables like $K_{T}^{0}, \Delta G_{T}^{0}, \Delta H^{0}$, and $\Delta S_{T}^{0}$. The data in Table 5 indicate that values of $K_{T}^{0}$ increased with rise in temperature from $25^{\circ} \mathrm{C}$ to $45^{\circ} \mathrm{C}$ ranging from 0.021 to 0.123 . Higher values of $K_{T}^{0}$ indicate the lower amount of $C_{e}$. The variations of $K_{T}^{0}$ with respective sorption temperatures may be due to soil pHs. The changes of $\mathrm{pH}$ have commonly been attributed to the preferential adsorption of $\mathrm{CdOH}^{+}$[40], the adsorption of $\mathrm{Cd}^{+2}$ [41], proton competition for adsorption sites [42], variation in the negative surface charge density of the soil $[2,43]$, and acid catalyzed dissolution of reactive oxide sites $[13,44]$ or precipitations as carbonates, hydroxides, and phosphates. In all soils, the free energy change $\left(\Delta G_{T}^{0}\right)$ of $\mathrm{Cd}$ sorption is positive and these values decrease with temperature which suggests the spontaneity of adsorption process with rise in temperature [45]. The spontaneity of 
TABLE 5: Thermodynamics variables on Cd sorption at reaction temperatures on experimental soils (data represent mean of tree replications $\pm \mathrm{SD})$.

\begin{tabular}{|c|c|c|c|c|c|}
\hline \multirow{2}{*}{ Sample ID } & \multirow{2}{*}{ Temperature $\left({ }^{\circ} \mathrm{C}\right)$} & \multicolumn{4}{|c|}{ Thermodynamics variables } \\
\hline & & $K_{T}^{0}$ & $\Delta G_{T}^{0}\left(\mathrm{kj} \mathrm{mol}^{-1}\right)$ & $\Delta H^{0}\left(\mathrm{kj} \mathrm{mol}^{-1}\right)$ & $\Delta S_{T}^{0}\left(\mathrm{j} \mathrm{mol}^{-1}\right)$ \\
\hline \multirow{3}{*}{$\mathrm{S}_{1}$} & 25 & $0.034 \pm 0.001$ & $8.41 \pm 1.79$ & \multirow{3}{*}{$8.07 \pm 1.97$} & $-1.15 \pm 0.78$ \\
\hline & 35 & $0.044 \pm 0.001$ & $7.99 \pm 1.38$ & & $0.26 \pm 0.03$ \\
\hline & 45 & $0.053 \pm 0.001$ & $7.76 \pm 1.09$ & & $0.96 \pm 0.01$ \\
\hline \multirow{3}{*}{$\mathrm{S}_{2}$} & 25 & $0.049 \pm 0.001$ & $7.48 \pm 1.21$ & \multirow{3}{*}{$7.10 \pm 2.29$} & $-1.26 \pm 0.12$ \\
\hline & 35 & $0.063 \pm 0.001$ & $7.07 \pm 1.37$ & & $0.10 \pm 0.001$ \\
\hline & 45 & $0.079 \pm 0.001$ & $6.71 \pm 1.41$ & & $1.24 \pm 0.61$ \\
\hline \multirow{3}{*}{$\mathrm{S}_{3}$} & 25 & $0.087 \pm 0.001$ & $6.06 \pm 1.21$ & \multirow{3}{*}{$5.81 \pm 1.01$} & $-0.82 \pm 0.002$ \\
\hline & 35 & $0.104 \pm 0.001$ & $5.81 \pm 1.73$ & & $0.01 \pm 0.001$ \\
\hline & 45 & $0.123 \pm 0.001$ & $5.54 \pm 1.91$ & & $0.86 \pm 0.17$ \\
\hline \multirow{3}{*}{$\mathrm{S}_{4}$} & 25 & $0.026 \pm 0.001$ & $9.03 \pm 1.73$ & \multirow{3}{*}{$8.79 \pm 2.01$} & $-0.82 \pm 0.02$ \\
\hline & 35 & $0.032 \pm 0.001$ & $8.80 \pm 1.07$ & & $-0.03 \pm 0.001$ \\
\hline & 45 & $0.040 \pm 0.001$ & $8.50 \pm 1.39$ & & $0.90 \pm 0.001$ \\
\hline \multirow{3}{*}{$\mathrm{S}_{5}$} & 25 & $0.021 \pm 0.001$ & $9.63 \pm 2.12$ & \multirow{3}{*}{$9.44 \pm 1.07$} & $-0.63 \pm 0.001$ \\
\hline & 35 & $0.024 \pm 0.001$ & $9.51 \pm 1.01$ & & $-0.21 \pm 0.001$ \\
\hline & 45 & $0.031 \pm 0.001$ & $9.16 \pm 2.09$ & & $0.89 \pm 0.03$ \\
\hline
\end{tabular}

sorption of Cd follows the order $\mathrm{S}_{3}>\mathrm{S}_{2}>\mathrm{S}_{1}>\mathrm{S}_{4}>\mathrm{S}_{5}$ and this is also the same agreement that was found in sorption isotherm.

The values of $\Delta H^{0}$ of $\mathrm{Cd}$ sorption were found to be positive and ranging from 5.81 to $9.44\left(\mathrm{kj} \mathrm{mol}^{-1}\right)$. The positive values of $\Delta H^{0}$ conform the endothermic $\mathrm{Cd}$ sorption process in soils and spontaneity is favored by high temperature. $\Delta H^{0}$ values follow the same trend that was found in $K_{T}^{0}$.

The values of $\Delta S_{T}^{0}$ were found positive at higher adsorption temperature $\left(45^{\circ} \mathrm{C}\right)$ and negative at $25^{\circ} \mathrm{C}$. For soil $\mathrm{S}_{4}$ and $S_{5}$ the values of $\Delta S_{T}^{0}$ were also negative. $\left|\Delta S_{T}^{0}\right|$ ranges from 0.01 to $1.26 \mathrm{j} \mathrm{mol}^{-1}$. The positive values of $\Delta S^{0}$ with higher temperatures indicate that the sorption of $\mathrm{Cd}$ is also favored by high temperature, whereas negative values cannot be able to bear the spontaneity of $\mathrm{Cd}$ sorption at lower temperature. However, the overall system in $\mathrm{Cd}$ sorption seemed to be endothermic, which may be attributed to the formation of different structural type of hydrated species of $\mathrm{Cd}$ ion and their movement from soil solution to soil. Roth et al. [46] reported that entropies are positive (just not for CS-MO) indicating that the adsorption is irreversible. Furthermore, entropies for the all soil are of the same order range as those determined on a soil from Aspach le Bas in Eastern France (Alsace-Haut Rhin) by Roth et al. [46].

\section{Conclusions}

Sorption of Cd was facilitated by temperature. At higher temperature $\mathrm{Cd}$ sorption was maximum in all experimental soils. Cd sorption data can be described satisfactorily by modified two surfaces, Langmuir isotherm and Freundlich isotherm. The conventional Langmuir equation failed to describe sorption of $\mathrm{Cd}$ in soils. The occurrence of Cd toxicity will be less in soil having higher $\mathrm{pH}$, clay content, $\mathrm{CaCO}_{3}$, and CEC. Acidic soils are more vulnerable to Cd toxicity; even a small initial concentration of Cd may account for problem of $\mathrm{Cd}$ pollution and its toxicity to plants and underground water. These results also demonstrate that increasing amount of indigenous soil organic matter may be the factor of $\mathrm{Cd}$ toxicity and its mobility in soils via the formation of soluble Cd-organic complexes.

On the basis of thermodynamic parameters, namely, $\Delta G$, $\Delta H$, and $\Delta S$, of adsorption kinetics it can be concluded that $\mathrm{Cd}$ sorption is endothermic and irreversible. Temperature always favors the sorption process. This observed phenomenon proves that the Cd toxicity in soils of India or other tropical countries would not be a serious problem due to more sorption of $\mathrm{Cd}$ by soils if temperature increases. Thus soil properties and soil environment particularly temperature need to be specially emphasized to minimize Cd toxicity in India or any other tropical country.

\section{Conflict of Interests}

The authors declare that there is no conflict of interests regarding the publication of this paper.

\section{Acknowledgments}

The authors gratefully acknowledge the helpful comments and suggestions made by the two anonymous reviewers of this paper. The authors are also thankful for the valuable suggestions of Dr. Sampa Das, Dibrugarh Polytechnic, Dibrugarh, Assam, India, during preparation of the paper.

\section{References}

[1] T. Karak and P. Bhattacharyya, "Heavy metal accumulation in soil amended with roadside pond sediment and uptake by 
winter wheat (Triticum aestivum L. cv. PBW 343)," TheScientificWorldJOURNAL, vol. 10, pp. 2314-2329, 2010.

[2] T. Karak, D. K. Das, U. K. Singh, and D. Maiti, "Influence of $\mathrm{pH}$ on soil charge characteristics and cadmium sorption in some noncontaminated soils of Indian subtropics," TheScientificWorldJOURNAL, vol. 5, pp. 183-194, 2005.

[3] Q. X. Zhou, X. Wang, R. L. Liang, and Y. Wu, "Effects of cadmium and mixed heavy metals on rice growth in Liaoning, China," Soil and Sediment Contamination, vol. 12, no. 6, pp. 851864, 2003.

[4] G. L. Guo and Q. X. Zhou, "Evaluation of heavy metal contamination in Phaeozem of northeast China," Environmental Geochemistry and Health, vol. 28, no. 4, pp. 331-340, 2006.

[5] A. Rathinam, B. Maharshi, S. K. Janardhanan, R. R. Jonnalagadda, and B. U. Nair, "Biosorption of cadmium metal ion from simulated wastewaters using Hypnea valentiae biomass: a kinetic and thermodynamic study," Bioresource Technology, vol. 101, no. 5, pp. 1466-1470, 2010.

[6] X.-F. Wang and Q.-X. Zhou, "Ecotoxicological effects of cadmium on three ornamental plants," Chemosphere, vol. 60, no. 1, pp. 16-21, 2005.

[7] T. Adhikari and M. V. Singh, "Sorption characteristics of lead and cadmium in some soils of India," Geoderma, vol. 114, no. 1-2, pp. 81-92, 2003.

[8] G. S. Miner, R. Gutierrez, and L. D. King, "Soil factors affecting plant concentrations of cadmium, copper, and zinc on sludgeamended soils," Journal of Environmental Quality, vol. 26, no. 4, pp. 989-994, 1997.

[9] M. Shirvani, H. Shariatmadari, M. Kalbasi, F. Nourbakhsh, and B. Najafi, "Sorption of cadmium on palygorskite, sepiolite and calcite: equilibria and organic ligand affected kinetics," Colloids and Surfaces A, vol. 287, no. 1-3, pp. 182-190, 2006.

[10] K. Wang and B. Xing, "Adsorption and desorption of cadmium by goethite pretreated with phosphate," Chemosphere, vol. 48, no. 7, pp. 665-670, 2002.

[11] C. A. Christophi and L. Axe, "Competition of $\mathrm{Cd}, \mathrm{Cu}$, and $\mathrm{Pb}$ adsorption on goethite," Journal of Environmental Engineering, vol. 126, no. 1, pp. 66-74, 2000.

[12] S. E. O’Reilly, D. G. Strawn, and D. L. Sparks, "Residence time effects on arsenate adsorption/desorption mechanisms on goethite," Soil Science Society of America Journal, vol. 65, no. 1, pp. 67-77, 2001.

[13] V. Antoniadis and C. D. Tsadilas, "Sorption of cadmium, nickel, and zinc in mono- and multimetal systems," Applied Geochemistry, vol. 22, no. 11, pp. 2375-2380, 2007.

[14] A. L. Horn, W. Reiher, R.-A. Düring, and S. Gäth, "Efficiency of pedotransfer functions describing cadmium sorption in soils," Water, Air, and Soil Pollution, vol. 170, no. 1-4, pp. 229-247, 2006.

[15] Š. Palágyi and J. Rigas, "Sorption of cadmium in some arable and forest soils," Journal of Radioanalytical and Nuclear Chemistry, vol. 261, no. 2, pp. 255-261, 2004.

[16] Å. Almås, B. R. Singh, and B. Salbu, "Mobility of cadmium-109 and zinc- 65 in soil influenced by equilibration time, temperature, and organic matter," Journal of Environmental Quality, vol. 28, no. 6, pp. 1742-1750, 1999.

[17] E. Pehlivan, M. Ersoz, M. Pehlivan, S. Yildiz, and H. J. Duncan, "The effect of $\mathrm{pH}$ and temperature on the sorption of zinc(II), cadmium(II), and aluminum(III) onto new metalligand complexes of sporopollenin," Journal of Colloid And Interface Science, vol. 170, no. 2, pp. 320-325, 1995.
[18] G. Sposito, The Surface Chemistry of Soils, Oxford University Press, New York, NY, USA, 1984.

[19] D. W. Nelson and L. E. Sommers, Methods of Soil Analysis. Part 3, Chemical Methods, SSSA Book Series no. 5, SSSA, Madison, Wis, USA, 1996.

[20] G. W. Gee and J. W. Bauder, "Particle size analysis," in Agronomy Monograph, vol. 9, ASA and SSSA, Madison, Wis, USA, 2nd edition, 1986.

[21] A. L. Page, Methods of Soil Analysis. Part II, Chemical and Microbiological Properties, Soil Science, Society of America Journal, Madison, Wis, USA, 1982.

[22] W. L. Lindsay and W. A. Norvell, "Development of a DTPA soil test for zinc, iron, manganese and copper," Soil Science Society of America Journal, vol. 42, pp. 421-428, 1978.

[23] P. W. Atkins, Physical Chemistry, Oxford University Press, Oxford, UK, 1982.

[24] J. E. Biggar and M. W. Cheung, "Adsorption of picloram (4amino-3,5,6-trichloropicolinic acid) on panoche, ephrata, and palouse soils: a thermodynamic approach to the adsorption mechanism," Soil Science Society of America Journal, vol. 37, no. 6, pp. 863-868, 1973.

[25] D. L. Dolcater, M. L. Jackson, and J. K. Syers, "Cation exchange selectivity in mica and vermiculite," The American Mineralogist, vol. 57, pp. 1823-1831, 1972.

[26] W. P. Inskeep and J. Baham, "Adsorption of $\mathrm{Cd}(\mathrm{II})$ and $\mathrm{Cu}(\mathrm{II})$ by Na-montmorillonite at low surface coverage," Soil Science Society of America Journal, vol. 47, no. 4, pp. 660-665, 1983.

[27] J. P. Hunt, Metal Ion in Aqueous Solution, W. A. Benjamin, New York, NY, USA, 1963.

[28] C. Appel and L. Ma, "Concentration, pH, and surface charge effects on cadmium and lead sorption in three tropical soils," Journal of Environmental Quality, vol. 31, no. 2, pp. 581-589, 2002.

[29] R. Levi Minzi, G. F. Soldatini, and R. Riffaldi, "Cadmium adsorption by soils," Journal of Soil Science, vol. 27, no. 1, pp. 1015, 1976.

[30] R. L. Reed, M. A. Sanderson, V. G. Allen, and R. E. Zartman, "Cadmium application and $\mathrm{pH}$ effects on growth and cadmium accumulation in switchgrass," Communications in Soil Science and Plant Analysis, vol. 33, no. 7-8, pp. 1187-1203, 2002.

[31] D. L. Sparks, Environmental Soil Chemistry, Academic Press, New York, NY, USA, 1995.

[32] J. E. Huheey, Inorganic Chemistry: Principles and Structure and Reactivity, Harper and Row, New Delhi, India, 8th edition, 2008.

[33] S. P. Singh, L. Q. Ma, and W. G. Harris, "Heavy metal interactions with phosphatic clay: sorption and desorption behavior," Journal of Environmental Quality, vol. 30, no. 6, pp. 1961-1968, 2001.

[34] N. J. Barrow, "Testing a mechanistic model. II. The effects of time and temperature on the reaction of zinc with a soil," Journal of Soil Science, vol. 37, no. 2, pp. 277-286, 1986.

[35] N. S. Bolan, D. C. Adriano, P. Duraisamy, and A. Mani, "Immobilization and phytoavailability of cadmium in variable charge soils. III. Effect of biosolid compost addition," Plant and Soil, vol. 256, no. 1, pp. 231-241, 2003.

[36] K. A. Bolton and L. J. Evans, "Cadmium adsorption capacity of selected Ontario soils," Canadian Journal of Soil Science, vol. 76, no. 2, pp. 183-189, 1996.

[37] G. W. Bruemmer, J. Gerth, and K. G. Tiller, "Reaction kinetics of the adsorption and desorption of nickel, zinc and cadmium by 
goethite. I. Adsorption and diffusion of metals," Journal of Soil Science, vol. 39, no. 1, pp. 37-52, 1988.

[38] J. K. Syers, M. G. Browman, G. W. Smillie, and R. B. Corey, "Phosphate sorption by soils evaluated by the langmuir adsorption equation," Soil Science Society of America Journal, vol. 37, no. 3, pp. 358-363, 1973.

[39] R. D. Harter and D. E. Baker, "Applications and misapplications of the Langmuir equation of soil adsorption," Soil Science Society of America Journal, vol. 41, pp. 1077-1079, 1977.

[40] R. Naidu and R. D. Harter, "Effect of different organic ligands on cadmium sorption by and extractability from soils," Soil Science Society of America Journal, vol. 62, no. 3, pp. 644-650, 1998.

[41] S. Sauvé, W. Hendershot, and H. E. Allen, "Solid-solution partitioning of metals in contaminated soils: dependence on $\mathrm{pH}$, total metal burden, and organic matter," Environmental Science and Technology, vol. 34, no. 7, pp. 1125-1131, 2000.

[42] A. E. Boekhold, E. J. M. Temminghoff, and S. E. A. T. M. van der Zee, "Influence of electrolyte composition and $\mathrm{pH}$ on cadmium sorption by an acid sandy soil," Journal of Soil Science, vol. 44, no. 1, pp. 85-96, 1993.

[43] R. Naidu, N. S. Bolan, R. S. Kookana, and K. G. Tiller, "Ionicstrength and $\mathrm{pH}$ effects on the sorption of cadmium and the surface charge of soils," European Journal of Soil Science, vol. 45, no. 4, pp. 419-429, 1994.

[44] H. A. Elliott and C. P. Huang, "The adsorption characteristics of $\mathrm{Cu}(\mathrm{II})$ in the presence of chelating agents," Journal of Colloid and Interface Science, vol. 70, no. 1, pp. 29-45, 1979.

[45] J. J. Jurinak and N. Bauer, "Thermodynamic of zinc adsorption on calcite, dolomite and magnesite type minerals," Soil Science Society of America Journal, vol. 20, pp. 466-471, 1956.

[46] E. Roth, V. Mancier, and B. Fabre, "Adsorption of cadmium on different granulometric soil fractions: influence of organic matter and temperature," Geoderma, vol. 189, pp. 133-143, 2012. 

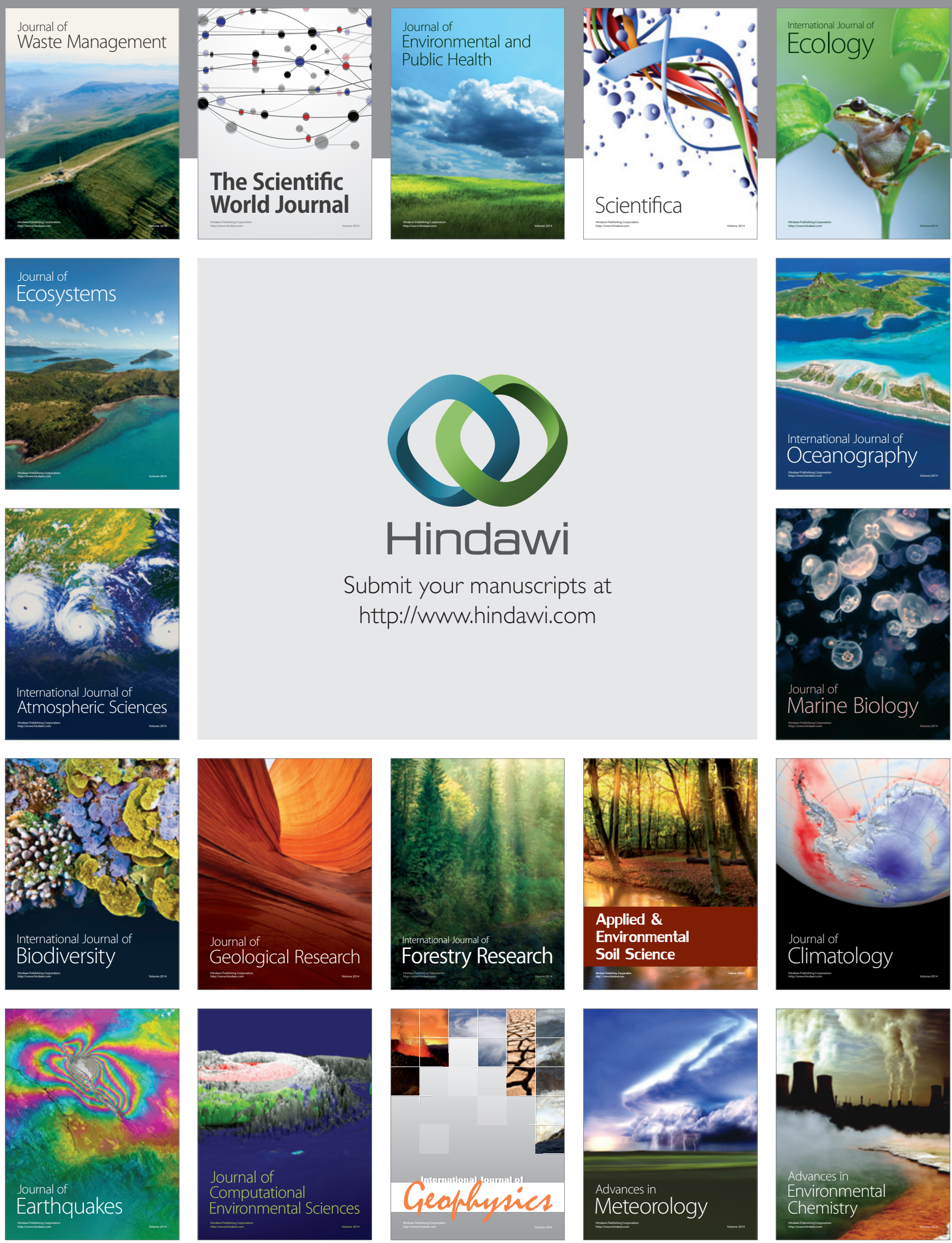